\title{
Astrolinguitics Of Ancient Coastal Minangkabau Community
}

\author{
M. Yunis ${ }^{1 *}$, Elly Delfia ${ }^{2}$ \\ Indonesian Literature Faculty of Cultural Sciences, Andalas University, Padang ${ }^{1}$ \\ \{yunissasda@gmail.com ${ }^{1}$ \}
}

\begin{abstract}
This research is the formulation of new ideas in the linguistic field. This study focuses on the signs and symbols of the ancient Minangkabau coastal community. This research approach is linguistics and astrology, then it is called astrolinguistics. This study aims to explain the astrological form of the ancient calendar system and explain the value system in the calendar system. So that it can be preserved and useful for national character education. This research is qualitative interpretative method with an Ethnometodological approach. The data obtained by means of field participation 'baguru method'. The baguru method is used to obtain sacred research data. The reserach results are calendar system is based on clasical astrology which has been used from generation to generation. This system has astrological symbols that are different from general astrology. Among them symbols of women, crosses, children, blanks and crowds. This astrolinguistic symbol marks the difference in time in one calendar day. In conclusion, the classical of calendar system there are five time sharing in one day.
\end{abstract}

Keywords: calendar; sign; linguistic; astrology and astrolinguistics

\section{Introduction}

The ancient dating method has long been applied by the Minangkabau Coastal community. This old calendar system is the main reference and determinant in the agenda of activities, both in the form of traditional activities and religious rituals. These traditional communities are not yet brave and cannot carry out activities if the date is not suitable.

For example, in determining the ceremonial implementation of marriage, people will refer to this ancient dating model. Starting with a matchmaking procession, inviting the community, and implementing events. The procession is adjusted to the good days and good months according to them. If the above procession does not match the calendar, it is feared that the event will harm the organizers. The public believes that the event will face many problems. For example, the rain or the absence of the event.

The ancient calendar has its own system of astrology which is different from general Astrology. This calendar has its own symbol (glyph) and each symbol determines the time. The symbols used coming from the natural surroundings, for example humans, animals, the environment, and others. The movement or position of symbols considered influencing human 
and the natural affairs. Meanwhile, astrology has glyphs in the form of planets and zodiac signs.

According to Balamurugun (2018: 5-7), astrology is the study of stellar science, an ancient science based on planets, the rotation of the sun and moon stars. The ultimate goal of astrology is to help people become aware of the constructive and destructive energies that the group of nine astronomical entities regularly releases. The movement and position of celestial bodies were interpreted as having an influence on human affairs and the natural world.

The researcher sees that the ancient calendar is also influenced by the position of the stars in the sky. The presence of symbols on the calendar can be interpreted as a condition of reality that is present on earth at that time. The interpretation of symbols as markers of good or bad time is one proof. As a result, there is a selection of recommended dates and times for activities. However, the study of ancient calendars must be approached by language science. Because, in this study it is loaded with the use of language symbols. Language symbols need to be interpreted more deeply so that they can be understood and understood.

Based on the description above, the relationship between linguistics and astrology give the opportunities of new knowledge development in social science clusters. Linguistics as a social science that focuses on the study of signs and symbols, will collaborate with the field of Astrology which focuses on astrology. This is done to bring linguistics into the realm of the open field. To get a more diverse study, it is fitting that linguistics collaborates with other sciences and called is Astrolinguistics.

\section{Literature Review}

The ancient calendar tradition is considered sacred by the owner, so not everyone knows and is expert in this calendar. Ancient dating is often referred to as a cross-cutting strategy. This strategy is used to organize movements for the Minangkabau community. The workings of the calendar are only controlled by certain people, such as Ulama Sataryah and traditional silat teachers. This calendar tradition is practiced in many ways, such as determining the good day of the month, both for traditional saremonial events, finding a mate, when working on the fields, fields, overseas trips, and so on.

This calendar tradition is full of language signs and symbols. These signs and symbols are interpreted based on the conditions of the stars in the sky which are represented by symbols of nature. Whether constellation changes cause weather changes for better or bad. The signs and symbols on this calendar are positioned in pairs, where the signs and symbols are positioned at each different angle. At the vertical angle the order of ten days is positioned, and at the horizontal angle the order of the five times of the day. Two angles of the position of different signs and symbols meet on the cross line which is shaped like a box, at this cross it can be seen the presence of occupying symbols. The cross between the day and the time represented by this symbol becomes a time formula that is categorized as good or bad. The interconnectedness of these symbols brings to mind how Astrology works. Therefore, the ancient calendar also known as classical star sciences by the Minangkabau communities.

The explanation above is the basis for researcher to formulate a new studies in the field of linguistics, which is called as Astrolinguistics. In simple terms, astrolinguistics itself is formulated into a branch of linguistics that examines signs, language symbols, and their relation to Astrology.The influence of the signs and symbols used on the sustainability of human activities. According to Rudresh M Shastri and A Rajagopal (2018), vedic astrology covers almost all important phases of human life. Likewise, Balamurugun (2019) stated that 
astrology is the study of stellar science, an ancient science based on planets, the rotation of sun stars and month. The ultimate goal of astrology is to evoke people awareness of the constructive and destructive energies that the group of nine astronomical entities regularly releases. Indeed, the movement and position of position of heavenly bodies were deciphered as affecting human issues and the natural world. Furthermore, Radhakrishnan (2017) examines ancient astrology which he calls Nakshatra. In this study, explain that of the twenty-seven birth stars, each includes the thirteen degrees and twenty minutes of the Zodiac. The constellation of stars in which the moon is placed at the time of one's birth is called Janma Nakshatra. It can describe a person's thinking patterns, traits, traits, destiny and instincts.

Then, Alexander Ollongren (2011) clarified that the interstellar message is figured in a language that is hard to comprehend. Meanwhile, the message beneficiary doesn't have a similar linguistic system as the sender of the message. To read the message, Ollongren offers the Lingua Cosmica or LINCOS system that can be used for cosmic message construction. This system is also used to read messages that have a different lingual symbol with the message reader.

In additional, Ivan (2009) said that there is a connection between celestial bodies and human activities on earth. For everyone has their own map of the sky and chart of birth. This birth chart shows the positions of the planets as well as their relative locations to one another at a certain date and time. Ivan tried to scientifically study that the events on earth were based on the position of the stars in the sky. This he describes in simple reference in the form of a map of the birth sky, related to the relations of the sun, mars, Jupiter, and other celestial bodies. From the many studies above, it is clear that humans are bound by the symbols contained in the concept of customs and habits. These symbols are made according to the need to face all possibilities and to overcome all obstacles in sheltering life. The symbol is functioned to fulfill the needs of daily life and the values it contains are passed on to the next generation who live in the community.

\subsection{Research Methods}

The astrolinguistic research on the ancient calendar aims to reveal cultural meanings through linguistic signs and symbols and their relation to astrology. These language signs and symbols are seen as the main archives for deconstructive reading of value systems and philosophies at the deepest level. As a field research, an interpretive qualitative method with an Ethnometodological approach is applied in this study. Bergman (in Kardoff, et al, 2017: 177-197) explained Ethnometodology is a sociological research approach that looks at social order with the overall consequences of its daily situations. It is considered as a product created methodologically by the members of society. A method like this really helps the writer in getting the data naturally.

In data collection, researcher uses participatory of involvement observation in the form of the baguru method. Then, the data analysis method used in this research was deconstruction and semiotic reading techniques (Piliang, 2018: 24--25). Deconstruction is meant not only to dismantle the text in the form of language signs and symbols, but also to try to build relationships between signs and symbols found in the object of research.

Based on this explanation, the data analysis stages will be sorted into several parts. Firstly, the data that has been collected is grouped based on research objectives. Secondly, the data is described in a structural form. Third, the data were analyzed by deconstruction to reveal an astrological form. Fourthly, the astrological form is interpreted with the help of semiotic/hypersemiotic theory. Fifthly, the meaning that has been found will be reformulated with an astrolinguistic approach, in order to formulate the value system contained in the object 
of study. Sixthly, making conclusions from the results of the discussions and analyzes that have been carried out.

\subsection{Research Results}

Astrological form of this calendar can be explained in the form and calendar system used, division of the day of the month, and division of time one day. The calendar system is more similar to the Hijri calendar in Islam, but it differs in pronunciation. The division of the months in this calendar remains twelve months. Interestingly, this calendar system does not stop at dividing the day, but continues to divide the time in one day into five important times.

On this calendar system there are twelve month naming. There are sura month of 30 days, sapa month of 29 days, muluk month of 30 days, adiak muluk month of 29 days, adiak muluk kaduo month of 30 days, caghai month of 29 days, sambagheh of 29 days, lamang month of 30 days, puaso month of 30 days, gayo month of 29 days, adiak gayo month of 30 days, and haji month of 29 days.

In this research the time division a one calendar day is divided into five times and each time is represented by a symbol. These symbols include; small children, girls, crowds, crosses, and blanks. The division of time in one calendar day starts from 12 noon or night. These 12 hours must be divided by five and each will add up to 2 hours and 40 minutes. The process of calculating time by dividing the hours above is adjusted to the division of the day in one month. Different month dates will result in a different step formula for each day. At 12: 00-02: 40 you can find a different symbol every day. If at one time you meet a child symbol, at that time you may not be allowed to do activities. If at one time you meet a female symbol, then at that time it is not recommended to do activities. Likewise, the time marked with a cross symbol includes times that are not recommended.

Time that is considered good is time marked with an empty symbol. On each day of the different calendar blank symbols can be found and sometimes not found. Time represented by an empty symbol is considered a good time and is recommended for carrying out activities. For more details, please note the form of a simple ancient calendar glyph below.

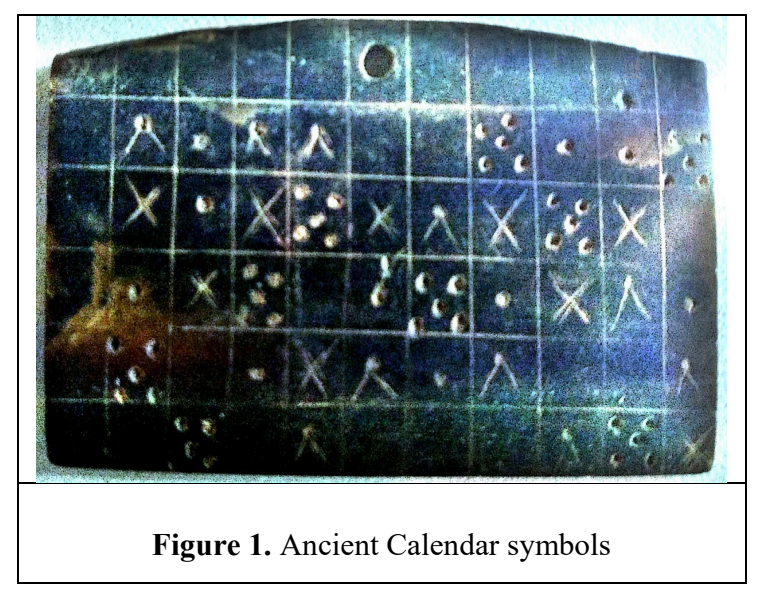

The change of the month is not an influence in the formulation of time. But it is the change in the date of the month that determines the pattern and the results obtained in the division of time. For example one calendar day falls on the 17th day of the month of the month. On the 
17th day of the lamang month it falls in the eighth box in the calculation of time. The count yields five symbols in a day which counts as 12 hours.

Time calculation is done by counting vertically in order from left to right up to the ninth box that already contains the symbols. Then the count to 10 returns to the first box on the left and so on until the count reaches 17 days of the calendar. In the box counting the days of the 17 th day, there is a child symbol, a five point symbol, a cross symbol, an empty symbol, and a female symbol.

The representation of semiotic and hypersemiotic structures of the calendar glyph in the time division on the 17 th day can be explained as below.

Table 1. Representation of time on the 17th day

\begin{tabular}{|c|c|c|c|c|c|}
\hline \multirow[t]{3}{*}{ No } & \multicolumn{5}{|c|}{ Semiotics/hypersemiotics } \\
\hline & \multicolumn{5}{|c|}{ Signifier } \\
\hline & Glyph & Signifier & signified & signified 2 & signified 3 \\
\hline 1 & 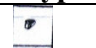 & point one & little child & 12:00--02: 40 & Not good \\
\hline 2 & $\because$ & point five & crowd & 02: 40--05: 20 & Not good \\
\hline 3 & $x$ & Cross & cross & 05: 20--07: 20 & Forbidden \\
\hline 4 & - & Empty & blank & 07: 20--09: 20 & Good \\
\hline 5 & $\bar{R}$ & bipet point & parampuan & 09: 20--12: 00 & Dangerous \\
\hline
\end{tabular}

The symbols produced on the 17 th day above are based on dividing the time into five parts of each day. Each time has a share of 2 hours and 40 minutes. Each time has its own glyph as shown in the table above, which represents the symbols of little children, crowds, crosses, blanks, and parampuan.

In the description of the table above the semiotic analysis ends in a signified whereas in the hypersemiotic analysis, the signified actually return to signified 2 and signified 3 . The basis for meaning like this refers to the hypersemiotic concept of meaning production. The signified 3 represents bad time including the time that is not recommended for doing activities. This time is represented by the symbols for a child, a five-point, a cross, and a girl. On the other hand, there is one good time that can be recommended to do an activity, which is the time represented by an empty symbol. Different of general Astrology, the timing in the calendar above is only based on five glyphs. These five glyphs or symbols are seen as something related to their external characteristics. In this case, the nature of women, the nature of children, the nature of cross, the nature of the crowd, and the empty nature. The physical properties of this symbol are then interpreted as a good sign or a sign of danger that will occur at that time.

\section{Conclusion}

In the ancient Minangkabau coastal traditional calendar system, there are 12 months as a reference. Among them; sura month, sapa month, muluk month, adiak muluk month, adiak 
muluk kaduo month, caghai month, sambagheh month, lamang month, puaso month, gayo month, adiak gayo month, and haji month.

The division of time in this calendar is carried out every calendar day. Each day there are five pieces of time, two times is bad, one time is forbidden, one time is better, and one time is dangerous. The each time is represented by a glyph based on its nature. The glyph includes a point one for a child, a point five for a crowd sign, a cross sign, a blank sign for safety, and a two-legged sign is point for marking abilities.

\section{References}

[1] Ollongren. (2011). Typing logic contents using Lingua Cosmic, International Journal Acta Astronoutica. V. 68, pp535-538.

[2] E. V. Kardoff, dkk (Ed.) (2017). Buku Induk Penelitian Kualitatif: Paradigma, Teori, Metode, Prosedur, dan Praktik. Yogyakarta: Cantrik Pustaka.

[3] I.Taniputera. (2009). Astrologi dan Sejarah Dunia. Jogjakarta: A+ Plus Book.

[4] P. Radhakrishnan. (2017). Integrated Evaluation on Malefic Nakshatra Attributes and Astrological Remedies, International Journal of Jyotish Research. V. 2, p 01-08.

[5] R. M. Shastri, and A Rajagopal. (2018). A Study on Gender Determination through Vedic astrology: Using Data Mining Techniques, International Journal of Jyotish Research. V. 3 (2), pp 09-14.

[6] S. Balamurugan, G. Thanganila, and R. Madhavan. (2019). Evaluation of diseases through astrological theory of siddhars, International Journal of Jyotish Research. V. 4, pp 05- 07.

[7] Y.A. Piliang, dan Audifax. (2018). Kecerdasan Semiotika, Melampau Dialektika dan Fenomena. Yogyakarta: Aurora. 